\title{
Several Misconceptions About Online Education
}

\author{
Lei $\mathrm{Yu}$ \\ Department of Foreign Languages \\ Shenyang Aerospace University \\ Shenyang, China \\ E-mail:yuleicathy@126.com
}

\author{
Yutong Qi \\ DUT-RU International School of Information Science \\ \&Engineering at DUT \\ Dalian, China \\ E-mail:1378603270@qq.com
}

\author{
Zhenguo Qi * \\ School of Educational Technology \\ Shenyang Normal University \\ Shenyang, China \\ E-mail:qizhenguo@126.com
}

\begin{abstract}
With the development of information technology, the term "online education" has become a household word, but the understanding of online education is not very clear. As a mode of education, online education has been widely concerned by educators and society. There have always been two main schools. One is advocating online education, believing that online education can complete educational teaching activities and achieve educational goals. The other holds that the network is only a technical means and transmission tool, which lacks the support of educational theories and cannot achieve an educational goal, while a correct understanding of it is the premise for the successful development of online education. It is of far-reaching significance for the development of online education to find out the misconceptions of online education and summarize the influencing factors of online education.
\end{abstract}

Keywords-online education; network teaching platform; online course; online learning

\section{INTRODUCTION}

Online education is advanced with the development of computer communication technology, Internet technology and modern education technology. This kind of education model has received great attention and controversy since it came into being in the early 1990s. There have always been two main schools. One is advocating online education, believing that online education can complete educational teaching activities and achieve educational goals. The other holds that the network is only a technical means and transmission tool, which lacks the support of educational theories and cannot achieve educational goals. Those who support it are mainly those who are engaged in technology, while those who do not support it are mainly those who study educational theory.

From the perspective of the development of online education in recent years, we can see that online education is mixed. It is necessary to analyze those online education projects which have invested a lot of funds and failed to achieve the desired results, and find out the reasons for their failure. Zhang Weiyuan, a Hong Kong scholar, pointed out in his article "An Analysis of the Reasons for the Success and Failure of Online Teaching in Foreign Colleges and

Fund project: The 13th five-year planning project of Education Science in Liaoning Province" Research on the success factors of online education". (Project No.JG18DB449)
Universities" (China Distance Education, 2005.11) that the main reasons for the failure of online teaching are: mistakenly believing that online teaching is to transfer existing courses to a large number of learners through the network to obtain high profits; mistakenly believing that online teaching is low-cost. The misconception is that prestigious universities can sell their courses directly to all parts of the world by virtue of their reputation without taking into account the actual local conditions and the characteristics of the learners. Through the case analysis of the failure of online education, we can see that the main reason for the failure of online education is the misunderstanding of it. It is of far-reaching significance for the development of online education to find out the misunderstanding of online education and summarize the influencing factors of it.

Definition of related concepts: The term "distance education" in China comes from the teaching mode of Radio and TV University, which is a form of correspondence education. The carrier of teaching transmission is tape, CD-ROM, video, radio and TV, etc. It is mainly the teaching form of "Radio and TV University" adopted in the 1980s. Since the 1990s, computers and the Internet have become the main carriers and transmission media of distance education. As one of the main forms of distance education, they are called "online education". Domestic scholars believe that " online education " is "E-learning" or "online learning", while foreign scholars believe that "E-learning" emphasizes electronic and digital learning, but do not think that "E-learning" is distance education or online education. For "online learning", domestic and foreign scholars basically agree that "online learning" is based on the network environment and the network can be either Internet or LAN, such as campus networks. "Online learning" is a mode of distance education. In Piskurich's (Piskurich, 2003) book "Online Learning Manual: Effective Design, Implementation and Technological Solutions", he proposed that "online learning is the learning using computer networks or the World Wide Web as a transmission or medium." Ally (2004) put forward that "online learning is the interaction between learners and learning content, teachers and other students through the network; learners get learning support services during the learning process, so as to acquire 
knowledge and grow from the learning experience".Gu Riguo, a domestic scholar, believes that "online education includes conceptually the development of online resources, students' access to resources, students' use of resources, students' generation of knowledge and skills, support services for students, evaluation and recognition of students' generated knowledge and skills, quality control and guarantee, and social recognition of quality." It is a complete system, not just a means. Can online learning be equated with online education? Gu Riguo believes that simply using the network as a means of teaching can only be regarded as online learning, rather than real online education. Online education is by no means the network of traditional education [1]. The connotation of "online education" defined in this paper is as follows: students and teachers are separated in space; computers and computer networks are the main transmission media; teachers and students carry out two-way communication feedback; learning is mainly collective learning, supplemented by individual counseling.

\section{MISCONCEPTIONS ABOUT ONLINE EDUCATION}

\section{A. Suitable learners for online education}

Misconception: Online education is popular education, suitable for all types of education.

Although online education has covered school education and social education, universities have online colleges and primary and secondary schools have online classes. However, the composition of learners and the characteristics of learners are the first elements that any educational institution must consider. The learner is the main body of educational activities. The learner's learning motivation, learning behavior and learning ability determine the success or failure of online education. Online education is suitable for adult education, not for minor education. From the perspective of age, online education is suitable for learners between 20 and 45 years old, who can be full-time students in school, on-the-job adult students, and on-the-job training staff in enterprises and institutions. Online education can be either an academic education or non-academic education. Full-time students (junior college students, undergraduate students and graduate students) are roughly the same in the age, learning the background, learning methods, learning time and so on, while adult students vary greatly. Therefore, online education for full-time students and on-the-job adults should be different. On-the-job adult learners are very clear about their learning goals and learning needs, so their learning is usually guided by problems in life and work, hoping to learn new knowledge and skills to solve current problems. They pursue the direct usefulness and efficiency of learning and like to learn while using, and they can restrain themselves and learn independently and have relatively rich learning and social experiences, which are favorable factors for online education, However, minors (primary and secondary school students) are dependent in learning and lack the ability of active self-learning, which are not suitable for online education.

\section{B. The number of students that can be cultivated by online education}

Misconception: Online education can train a large number of students at the same time, and even believes that online education is not limited by the number of students.

The learner's online learning is mainly realized through the network courses and the network teaching platform. At present, there is no definite conclusion about how many students are suitable for a course to carry out online learning. The learner's self-learning ability and motivation to participate in online learning directly affect the number of online learners of a course. The number of adult learners can be more in online courses, but for minors (such as primary and secondary school students), it is not suitable to adopt the online education model. The nature of curriculum, the content of courses and the methods of assessment will also affect the number of online learners.

Academic education is a type of education which its assessment requirements are relatively specific and strict, so the number of online course learners should not be too large. The more direct constraints are not from the curriculum itself or the learners themselves, but mainly from the management of online education. It is unrealistic for a course to rely solely on students' self-study on the Internet, at least for the vast majority of students. Each course requires professional teachers to guide and answer questions, and to interact with students. The number of these professional teachers limits the number of students who study online. From the past experience, a teacher can counsel 50 students online, whose workload is already very large. 50 is basically the upper limit of the number of students, so we can deduce that the size of a class online had better not exceed 50 students. [2] Increasing the number of tutors and the contribution rate of technology to curriculum guidance is the way to expand the number of students participating in online learning.

\section{The cost of online education}

Misconception: The cost of online education is low.

"Cost" is the concept of economics, which refers to all the expenses of a product; "Education Cost" refers to all the expenses directly and indirectly paid by the society and the learners themselves to train a learner,, including the explicit cost that can be calculated, and the implicit cost that is not easy to calculate. Whether the cost of online education is low or not, there may be different answers from different perspectives. The conclusion that the cost of online education is low is basically calculated from the perspective of network course production. In fact, the cost of online education includes not only the cost of network course production but also the cost of hardware environment construction, teaching management and teaching implementation, some of which are explicit and computable, while others are implicit and difficult to calculate. Scholars at home and abroad have made a full study of the cost-effectiveness of online education. Greville Rumble divides the cost of online education into the cost of online resource development, the cost of online resource transmission, the cost of daily management and infrastructure. [2] Brian M. Morgan, a scholar at Marshall University in the United States, classifies the cost of online education into technical characteristics cost, 
human support cost, administrative management cost, curriculum development cost, curriculum teaching cost and hidden cost. [3] Wu Gengsheng and Li Haixia of Tsinghua University divide the cost of online education into development cost, transmission cost, teaching and support cost, daily management and infrastructure cost, and according to the nature of expenditure of public institutions in China, they divided the cost into labor cost, public cost and fixed asset cost. [4]

It is considered that the low cost of online education is mainly due to the lack of calculation of the total cost of online education. From the perspective of network colleges and other online teaching institutions, the main investment is in the construction of hardware and curriculum development, while the investment in the construction and management of teachers' team is relatively small. More attention is paid to the education cost of schools or network colleges, less to the education cost of learners. The development cost and transmission cost of online courses will decrease with the passage of time. In addition, the cost of online education is closely related to the size and quantity of learners. Generally, the one-time investment of hardware facilities will reduce the average cost of online education with an increase in the number of learners.

\section{Teaching quality of online education}

Misconception: The quality of online education is lower than that of traditional education

There are several reasons for this understanding: first, online education institutions such as network colleges blindly pursue scale efficiency, ignore teaching quality management, and do not strictly check the "entrance" and "exit" of students, which affects the social reputation of online education. The second is the short time of online education. The society does not have enough or even a wrong understanding of online education so that some employers boycott and repel the talents of online education, who think that the online education degree is low. Third, there is a lack of strict examination on the source of students entering the online education, and the source of students in the network colleges cannot be strictly selected as those in the college entrance examination. Fourthly, the educational resources provided by online education are insufficient, which can't meet the needs of online education.

It is meaningless to compare online education with traditional education under unequal conditions. Learning tasks, learning motivation, characteristics of learners, teaching methods and so on affect the quality of teaching. As long as online education follows the laws and basic principles of education, properly uses technology and methods and effectively promote the communication and exchange between teachers and students, between students and students, the quality of online education is not inferior to the traditional school education, which has been confirmed by non- academic education such as enterprise training.

\section{E. Time and place of online education}

Misconception: Online education is not restricted by the time and place of study

Some people think that online education is not restricted by time, place and space, and can be studied online anytime and anywhere. This is the goal that online education has been pursuing. It is an ideal state, and the actual situation can't be achieved. Online education is restricted by computer equipment and network communication, which will be solved gradually with the development of mobile learning terminal equipment (such as mobile phones, iPad, etc.) and the Internet, communication technology. In addition, learning needs a quiet and undisturbed place, which cannot be achieved in the home and office. Sometimes, a phone call or message will disturb the learning interest and thoughts, and if this happens frequently, the learning cannot continue. Learners who decide to carry out online learning usually need to make a complete course learning plan. Once the learning plan is made, the learning time is basically limited. If the plan cannot be completed normally due to emergencies or interruptions in the learning time, it is not realistic that online education is not limited by the learning time.

\section{F. Online education and individualized learning}

Misconception: Online education is suitable for individualized and differentiated learning

In online education, the database management technology and two-way interactive function enable the computer system to track and record each learner's personal data, learning process, learning status, etc. and different learning plans and learning suggestions are made for different learners according to the results of tracking and recording. However, the satisfaction and adaptation to individual needs are limited. On the one hand, the teaching plan, teaching content and teaching resources are generally prepared and arranged by the teachers who can only consider the needs of most learners, not the requirements of every learner. Some learners mistakenly believe that online education can make plans and provide individual guidance for each learner, but online teachers do not have enough time to provide individual guidance for each student. [5] Generally, teachers only coach and deal with the common problems, let alone "teach students in accordance with their aptitude ". The so-called individualized differential learning in online education usually means that learners choose suitable learning content and learning methods according to their own learning characteristics, learning ability and learning needs. For example, they can repeatedly watch a section of classroom records, repeat online tests, browse the content they are interested in many times, and reasonably allocate their own learning time, etc. On the premise of abundant teaching resources, individualized differential learning at this stage can only be achieved by learners "taking what they need".

\section{G. Online education and autonomous learning}

Misconception: Online education can realize learners' autonomous learning

There are basically two modes of online education in our country: one is to provide a network teaching platform, which provides online courses and related learning resources, including video and audio materials, text materials, animation, courseware and other multimedia materials; for example, the course record (video) taught by the teacher, the lecture notes (text) of the teacher, the reading materials provided by the teacher to the students, and the periodic tests, etc. Teachers make curriculum learning plans and arrange online teaching 
and learning activities. Students regularly download learning tasks and upload assignments on the Internet according to teachers' arrangements, and interact with teachers to complete learning tasks. This mode is an organized teaching mode, and students have less freedom. Another mode is to send the course materials and learning CD-ROM to students, which includes the teacher's actual records and related learning contents. Students arrange their own time to watch and learn, and regularly visit the course's learning website to participate in community discussion and Q \& A. In this mode, learners have a high degree of freedom, but the proportion of completing their studies is not high. If this mode of online education is adopted, the requirements for learners' self-discipline and self-control ability are very high, so it is difficult for ordinary learners to adhere to it. Most learners can adhere to it for a while as starting learning, and often interrupted by all kinds of things, then study nervously as the examination draws near, so the effect is very poor. Most network colleges adopt the first mode, and learners can't really achieve autonomous learning.

\section{$H$. Technical requirements for learners in online education}

Misconception: Learners who study online need to have good computer skills

The requirements of online learning for the computer knowledge and operation ability of learners are not high. Generally, only some basic computer operations are needed. The learners can visit the learning website, download and upload materials, send and receive emails, chat with words, etc. Usually, the online teaching platform or learning website will have a more detailed operation guide and instructions. Learners can learn to use online teaching platform to participate in online course learning as long as they follow the steps of operation guide. In the process of online learning, it is necessary to learn some network application skills, such as how to quickly and accurately retrieve the required materials, how to effectively communicate with people online, how to avoid the interference of network redundant information to improve the efficiency of online learning.

\section{About online courses}

Misconception: Online courses are a good form of courses, most of which are suitable online
Not all subjects and courses are suitable for online teaching, and the ones that are suitable for making online courses are usually: the learning content contains a large number of resources such as text, graphics, images, animation, video, sound, etc., which students can't make good use of to complete the learning tasks in the ordinary classroom. For the simple content that students can master only by reading the textbook, it is not necessary to make it into an online course. We should not make all courses into online courses because of the pursuit of online education, which is not in line with the law of education and the accounting of education cost-benefit. Only by selecting suitable materials and using them properly can we give full play to the effect of online courses and play a more effective role in teaching.

\section{CONCLUSION}

Online education is a complex system engineering, and many factors will affect the success of online education, among which the understanding of online education is one of the important ones. To some extent, the correct understanding of online education is the decisive factor for the success of online education, and the correct understanding of online education is the premise for the decision-making of online education.

\section{REFERENCES}

[1] Zhang Weiyuan, Wu Tingjian, "The development of online learning and the formation of three theoretical schools.” Distance education in China, vol.9, pp. 9-14, Sept.2013.

[2] Wang Qiong, “ Four elements of online teaching success,” Beijing: Peking University Press, 2011.

[3] Brian M.Morgan, "Is Distance Learning Worth It? Helping to Determine: the Costs of Online Courses," http: //www.marshall.edu/distance/distance learning .pdf.

[4] Wu Gengsheng, Li Haixia, "Cost analysis and comparison of Network College: a case study of Tsinghua University,” Distance education in China, vol.1, pp. 23-26, Jan.2012.

[5] Qi Zhenguo, Wang Qiong, “Challenges brought by E-learning for college teachers in China," China audiovisual education, vol.7, pp. 21-25, July 2009 